The Egyptian Journal of Hospital Medicine (October 2018) Vol. 73 (10), Page 7778-7784

\title{
Prevalence of Stress among Female Medical Students at AL-Maarefa Colleges
}

\author{
Mona A Alfadeel,Asil MHD Khalid Alhomsi, Abrar Ahmed Aldeera, Amjad Omar \\ Alhussaini, Doaa Ali Al-Laili, Fatima Saleh Ali, Hind Mustafa Mona, Kawthar Ali \\ Almarhoon, Ola Abdullah Khalaf, Shahd Abdullah Abdulwahab, Yossra Alaaddine \\ Benhadi, Zainab Ali Alabbas*
}

College Of Medicine, Al-Maarefa Colleges for Science \& Technology, Riyadh, Saudi Arabia

*Corresponding author: Zainab Ali Alabbas, Email: ehsas-z-@ hotmail.com, Mobile number: +966565151929

\begin{abstract}
Background: Stress is a state of mental tension and worry. A study was conducted in Al Maarefa Colleges, College of Medicine in a sample of 130 female medical students to assess the prevalence of stress.

Objectives: This study aimed at determining the prevalence and levels of stress in female medical students. Association of stress with some factors was determined.

Method: This was an observational, descriptive, cross-sectional study in which a sample of randomly collected female medical students between $3^{\text {rd }}$ and $8^{\text {th }}$ level completed a selfadministrated questionnaire. SPPS was used to analyze data and Chi-square test to investigate the association of the proposed variables.

Results: students in level 7-8, 78\% who were single, $82 \%$ of students who studied 2-4 hours/day, $77 \%$ of students who chosed their specialty based on their own desire, and $79 \%$ of students who had a relationship with their family had low stress. There was a significant association between the adaptation to frequent exams and the levels of stress. $(\mathrm{p}=0.048)$. Otherwise, there was no statistical association between any of the other factors such as hours/day spent on studying, the method of tuition payment or choice of specialty and stress.

Conclusion: It was found that the majority of the students had low levels of stress. The highest proportion of low stress was in those who were in level 7-8 and those who were not adapted to frequent examination. It was found that those who had good relations with their family, teachers and colleagues had a low level of stress.
\end{abstract}

Keywords: Prevalence, Stress, Female, Medical Student.

\section{Introduction}

It has been hypothesized that exposure to stress and negative life events is related to poor health outcomes, and that differential exposure to stress plays a role in socioeconomic disparities in health ${ }^{(1)}$. One of the major obstacles concerning stress is that the term "stress" is used by the public as an umbrella to describe anything including the usual blues that people all suffer from time to time. It is partly due to this lack of knowledge that many cases of stress go undiagnosed and untreated. Medical students are faced with demanding academic standards, deadlines, career aspirations, and the need to compete for residency positions ${ }^{(2)}$. Stress can lead to many other problems. It can result in feelings of rejection, anger, and depression, leading to health problems such as headaches, upset stomach rashes, insomnia, ulcers, high blood pressure, heart disease, and stroke ${ }^{(3)}$. Medical students are expected to learn and master a huge amount of knowledge and skills. Stress has serious consequences, which may lead to the development of depression and anxiety. Studies on psychological problems such as stress, depression and anxiety among medical students have found that these disorders are under-diagnosed and undertreated. Failure to 
detect these disorders, unfortunately, leads to increased psychological morbidity with unwanted effects throughout their careers and lives.

A study made in 2015 by Alfaisal University in Riyadh, Saudi Arabia was designed to assess the traits of depression, anxiety, and stress among students. A total of $76.8 \%$ and $74.9 \%$ of students participated in pre- and post-examination groups, respectively. The majority were the children of expatriate workers in Saudi Arabia and included Arabs, South Asians, and North Americans. Prevalence of depression, anxiety, and stress was high $(43 \%, 63 \%$, and $41 \%$, respectively) which reduced (to $30 \%$, $47 \%$, and $30 \%$, respectively) to some extent after examinations ${ }^{(4)}$.

A study in 2014 designed to assess the traits of depression, anxiety, and stress among students and pharmaceutical students in the Alexandria University of Egypt. With a total number of 164 students, the prevalence of anxiety and depression was found to be $43.9 \%$ and $57.9 \%$. In the Faculty of Pharmacy, with a total number of 164 students was found to be $29.3 \%$ and $51.1 \%$. The result was in the Faculty of Medicine were found higher than that in the Faculty of Pharmacy and the prevalence of symptoms was higher among females ${ }^{(5)}$.

A study was conducted at Australian Sydney University from March to September 2011 about the relationship between medical school stress and they conducted an anonymous online survey. The students rated the stressors as following: study and examinations $(48.9 \%)$, financial concerns (38.1\%), isolation (19.4\%) and relationship concerns $(19.2 \%)$ as very or extremely stressful issues. Knowledge of available support services was high, with $90.8 \%$ indicating they were aware of the university's medical center. Treatment rates were modest $(31.7 \%)^{(6)}$.
A study at Johns Hopkins School of Medicine was carried out in September 2009 with the entering cohort (2013 batch) to study stressors in medical students. The Number of participants was $110(>90 \%)$ in 2009 and it decreased to $70(60 \%)$ to the beginning of the fourth year in 2012. Although medical students have the lower mean score in stress scale (perceived stress scale) in general, there was an increase unadjusted stress score at the beginning of the second year and then again beginning of the fourth year (highest). Stress score change from baseline to the beginning of the fourth year was statistically significant $(11.42+/-5.75$ vs. $15.46+/-6.43, \mathrm{p}=$ $<0.0001)$. During four year period, 1 student met criteria for severe depression and 5 for moderately severe depression and 7 for mild depression; it showed that medical students have increased stress and depression score at the beginning of second and fourth years ${ }^{(7)}$.

A study done in 2011 in King Saud University in Saudi Arabia to address psychological distress and depressive diseases among medical students. The study included all male and female medical students in all five academic years of KSU. The prevalence of stress was the highest among the first-year students $(78.7 \%)$, followed by the second-year $(70.8 \%)$, thirdyear $(68 \%)$, fourth-year $(43.2 \%)$, and fifthyear students $(48.3 \%)$. There was a highly significant association between the study year and the stress levels. The main sources of stress stated by the students were coping with their studies $(60.3 \%)$, followed by home environment (2.8\%). However, 36.9\% of the students did not mention any source of stress (8).

In a study about stress in medical students at a the University Of Stockholm, Sweden in 2005 the students are asked to complete two inventories, Higher Education Stress Inventory and Major Depression Inventory to assess the exposure to different stressors and the prevalence of depression among medical students at different levels of education, taking gender differences into account. The results were that stress levels we have seen to be high across all years, 
higher in year 1 than in year 3. The result of comparing the depression rate with the general population they saw that there was a much higher percentage rate in medical students than in the general population was $12.9 \%$, and stress was $16.1 \%$ among female students versus $8.1 \%$ among male ${ }^{(9)}$.

\section{Problem statement:}

Nowadays, stress plays an important role in the school, especially among medical students. In fact, the prevalence of stress is $70 \%$ higher during the initial three years of medical school. Medical students are overloaded with the tremendous amount of information. They have a limited amount of time to memorize all the information studied. The overload of information creates a feeling of disappointment because of the inability to handle all the information at once and succeed during the examination period. Previously, limited numbers of studies have been done about medical students associated with stress and depression. Today's medical learners are the future healers of the community people of Saudi Arabia. A medical student who has battled depression on and off for the past 4 years wrote: "if there was one thing I could implement in medical schools is that there would be more attention paid to the mental health of students, because I believe that only when we are healthy that we can begin to treat others. Mental health is regarded as an essential component of health by the World Health Organization and since prevention is better than cure the purpose of this study was to understand the factors that contribute to this problem and help decrease, prevent or eliminate them. It was therefore important to be aware of the symptoms of psychological stress in medical students, especially those that are associated with stress in order to facilitate early detection and offer help to these problems.

\section{Objectives:}

- To assess the prevalence of stress among female medical students in the first 3 years of the medical faculty at Al Maarefa Colleges 20152016.
- To determine the level of stress of female medical students from the 1 st year to 3 rd year of medicine.

- To determine the association between several risk factors and the level of stress.

\section{Methodology}

Study design: it was an observational, descriptive, cross-sectional design.

Study area: The study was conducted at $\mathrm{Al}$ Maarefa Colleges for Science and Technology (MCST) located in the city of Riyadh - Diriyah of the Kingdom of Saudi Arabia. Al Maarefa Colleges was established in 2009. Al Maarefa colleges consist of three colleges: College of Medicine, College of Pharmacy and College of Applied Sciences (10-14).

The population of the study was female medical students post-preparatory and preclinical from level 3 to level 8. Excluding all other female medical students in the preparatory year and clinical years and from non-medicine colleges and male students in all colleges.

Sample size and technique: We used the following equation to calculate the sample size.

$\mathrm{SS}=\frac{Z^{2} *(P) *(1-P)}{C^{2}}$

Where:

$\mathrm{Z}=\mathrm{Z}$ value (e.g. 1.96 for $95 \%$ confidence evel) decimal

$\mathrm{P}=$ percentage picking a choice expressed as

(.5 used for sample size needed)

$\mathrm{C}=$ confidence interval expressed as a decimal

(e.g. $04= \pm 4)$

$\mathbf{S S}=(1.96)(21)(79) /(4.2)^{\wedge} 2=184$

The sample size collected was 130 .

We used convenience sampling technique to choose the sample from female medical students between levels 3 and 8 . 


\section{Data collection tools:}

We used pretested, self-administered questionnaire specially designed for this study. It contained open and closed-ended questions about the demographic data and the stressors included in our study.

- $\quad$ Cohen's scale had been used to assess the level of stress among students. In this scale Individual scores on the $((\mathrm{PSS}))$ "Perceived Stress Scale" can range from 0 to 40, scores ranging from 1-13 would be considered low stress, scores ranging from 14-26 would be considered moderate stress, and scores ranging from 27-40 would be considered high perceived stress.

\section{Data analysis:}

- After collection of data, clearance and coding, we used SPPS for the entry and analysis of our data

- We investigated the distribution of variables using Chi-square test.

Ethical issue: before starting the study, permission was obtained from the college administration. The consent of the participants was obtained as well. All participants were assured that any private information and data collected will not be divulged or used for any other purposes.

\section{Results}

Table 1 shows that $82 \%$ of students who were at level 7-8 had low stress, $78 \%$ of students who were single had low stress.

Table 2 demonstrates that $82 \%$ of students who studied 2-4 hours/day had low stress, $79 \%$ of students who had a scholarship had low stress, $83 \%$ of students who lived far from university had low stress, $82 \%$ of students not adapted to the frequent exams had low stress, $77 \%$ of students who chose their specialty based on their own desire had low stress, $79 \%$ of students who had a good relationship with their parents had low stress, $76 \%$ of students who had a good relationship with their colleagues had low stress, and $77 \%$ of students who had a good relationship with their teachers had low stress. There was a significant association between the adaptation to frequent exams and the levels of stress. $(\mathrm{p}=0.048)$. Otherwise, there was no statistical association between any of the other factors and stress.

Table 1: Demographic data and level of stress $(\mathrm{N}=130)$

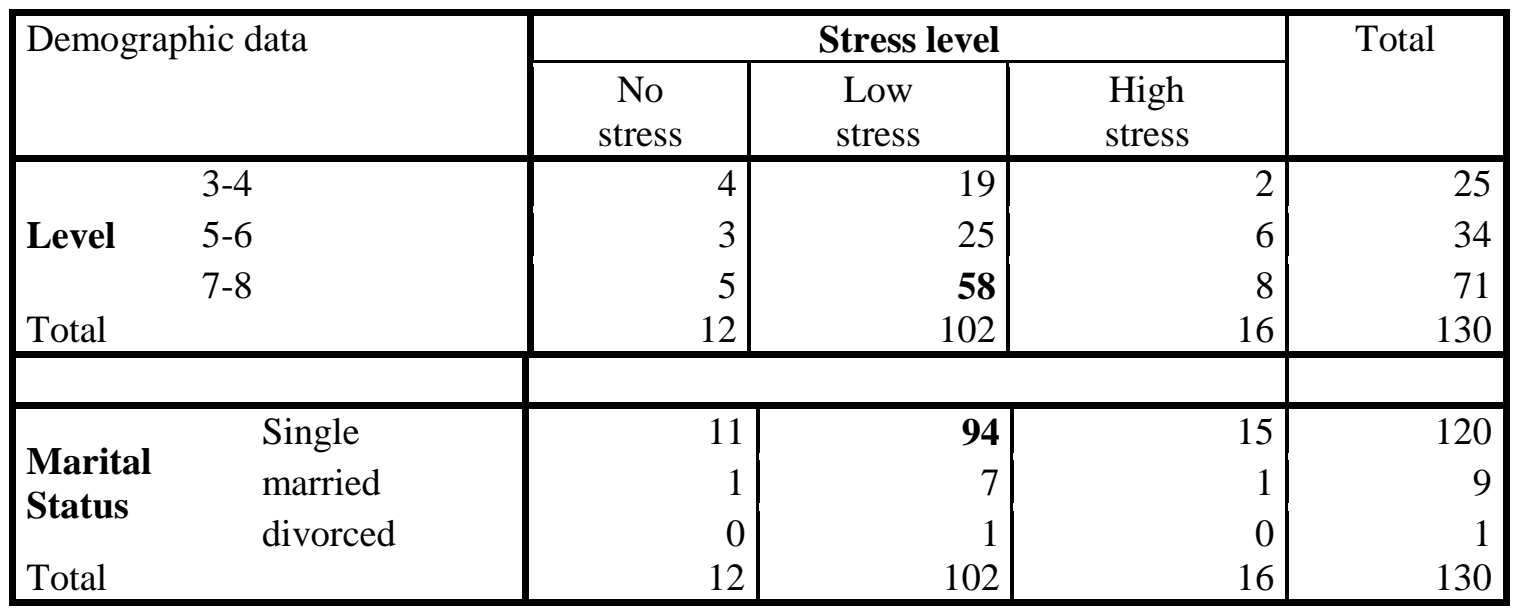

Eighty two percent of students who were at level 7-8 had low stress, $78 \%$ of students who were single had low stress. 
Table 2: stressors and level of stress $(\mathrm{N}=130)$

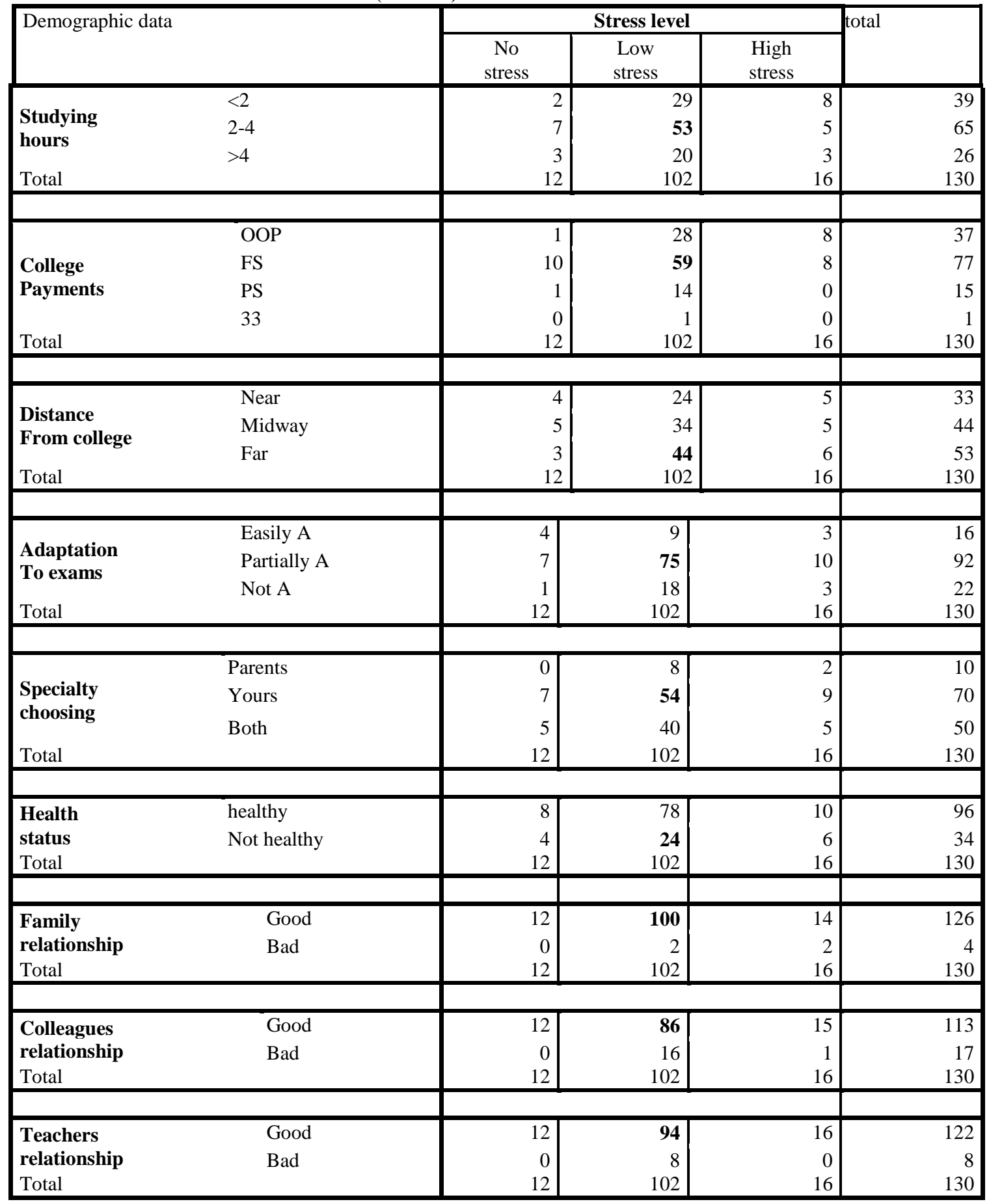

Eighty two percent of students who studied 2-4 hours/day had low stress, $79 \%$ of students who had a scholarship had low stress, $83 \%$ of students who lived far from university had low stress, $82 \%$ of students not adapted to the frequent exams had low stress, $77 \%$ of students who chose their specialty based on their own desire had low stress, $79 \%$ of students who had a good relationship with their parents had low stress, $76 \%$ of students who had a good relationship with their colleagues had low stress, and $77 \%$ of students who had a good relationship with their teachers had low 
stress. There was a significant association between the adaptation to frequent exams and the levels of stress.

\section{Discussion}

Exams seem to be one of the main stressors in students' lives. The significant association between adaptation to frequent exams and level of stress support this statement. It is natural and expected that exams are a stressor among medical students. Medical students in Almaarefa colleges face an exam almost every week. Majority of the students identified frequent exams as a stressor which was similar to a study conducted in Thailand that showed exams to be the strongest cause of stress ${ }^{(10)}$.contrary to a study conducted in Australia showed that only $48 \%$ of the students' stress was exam related ${ }^{7}$. This study showed that more than half of stressed students were at 4th year while a study conducted in the USA showed that medical students have increased stress and depression score at the beginning of second and fourth years ${ }^{(3)}$. In this study, the stress levels seen were low. This is similar to the stress levels seen in the Canadian Medical Schools which were mild, with very small numbers reporting high levels of stress ${ }^{(11)}$. And this is contrary to a study done at King Saud University where their result showed that medical students experience higher levels of stress than other specialties ${ }^{(11)}$. This study showed that people on the unhealthy diet had the low level of stress contrary to a study done in Iraq showed that a nonnutritious diet and few bad eating habits were associated with high levels of stress ${ }^{(12)}$.

\section{Conclusion}

It was found that the majority of the students had low levels of stress. The highest proportion of low stress was in those who were in level 7-8 and those who experienced frequent exams. The good relationship with family, teachers and colleagues were associated with low level of stress.

\section{Recommendations}

- University should provide extracurricular activities and clubs to help reduce the student's stress and avert their mind from solely studying.

- Students should make time to engage in physical exercise at least 3 times/week and have a social life to help reduce the stress.

- Future studies are required to evaluate stress and its factors should be done.

\section{Acknowledgement:}

We would like to express our special thanks of gratitude and appreciation to our supervisor Dr. Mona Hassan who taught us how to do a research properly and professionally. And so this project is attributing to her help.

Secondly we would also like to thank the families and friends who encouraged each one of us to exert their utmost efforts in order to finalize this project within the limited time frame.

\section{References}

1. Lantz P, House J, Mero $\mathbf{R}$ et al.(2005): Stress, life events, and socioeconomic disparities in health: results from the Americans' Changing Lives Study. Journal of health and social behavior, 46(3): 274-288 2. Badr H, Hamoda H (2005): Stressors and coping strategies of medical students. Gender differences. Saudi medical journal, 26(5):890-892.

3. Behere S, Yadav R, Behere P (2011): A comparative study of stress among students of medicine, engineering, and nursing. Indian journal of psychological medicine, 33(2): 145.

4. Kulsoom B and Nasir A (2015):Stress, anxiety, and depression among medical students in a multiethnic setting.Neuropsychiatric disease and treatment, $11: 1713$.

5. Walter G, Soh N, Jaconelli, S et al. (2013): Medical students' subjective ratings of stress levels and awareness of student support services about mental health. Postgraduate Medical Journal, https://www.ncbi.nlm.nih.gov/pubmed/2346 8555

6. Ranasinghe P, Lau B, Defoe D et al. (2014): Stress and Depression Among Medical Students During Four Years in 
Medical School. Journal of Hospital Medicine,2014: 9.

7. Al-Asadi J (2014): Perceived Stress and Eating Habits among Medical Students. International Journal of Medicine and Pharmaceutical Sciences, 4: 81-90.

8. Abdulghani H, AlKanhal A, Mahmoud E et al.(2011): Stress and its effects on medical students: a cross-sectional study at a college of medicine in Saudi Arabia. Journal of health, population, and nutrition, 29(5): 516.

9. Dahlin M, Joneborg N, Runeson B (2005): Stress and depression among medical students: A cross-sectional study. Medical education, 39(6): 594-604.

10. Ibrahim $M$ and Moataz $H$ (2015): Prevalence of anxiety and depression among medical and pharmaceutical students in Alexandria University." Alexandria Journal of Medicine, 51:167-173.

11. Saipanish R (2003): Stress among medical students in a Thai medical school. Medical teacher, 25(5):502-506.

12. Helmers K, Danoff D, Steinert Y et al.(1997): Stress and depressed mood in medical students, law students, and graduate students at McGill University. Academic Medicine, 72(8):708-714. 